\title{
Transplante de córnea em ceratite por herpes simples
}

\author{
Corneal transplantation for herpes simplex keratitis
}

\author{
Maria Emília Xavier dos Santos Araújo ${ }^{1}$ \\ Namir Clementino Santos ${ }^{2}$ \\ Denise de Freitas ${ }^{3}$
}

\section{RESUMO}

Objetivo: Avaliação de transplante de córnea em ceratite por herpes simples. Métodos: Foram revisados os prontuários de 38 pacientes submetidos a transplante de córnea por herpes simples, no período de 1993 a 1998. Todos os pacientes tinham apenas um olho acometido. Foi avaliada a transparência do botão corneano, reação de rejeição, recidiva da infecção herpética e acuidade visual final. Pacientes que usaram profilaxia antiviral foram comparados com os que não usaram. O seguimento pós-operatório variou de 6 a 68 meses (média de 21). Resultados: Trinta e um enxertos $(81,6 \%)$ permaneceram transparentes. Reação de rejeição ocorreu em 14 pacientes $(36,8 \%)$ e recidiva da ceratite herpética em $4(10,5 \%)$. A acuidade visual pós-operatória foi melhor ou igual a 0,25 em $60 \%$ dos pacientes. Não houve diferença estatisticamente significante na sobrevivência do enxerto entre o grupo que usou e o que não usou antiviral sistêmico profilático. Conclusão: Melhores resultados têm sido alcançados no transplante de córnea em ceratite herpética.

Descritores: Transplante de córnea; Ceratite herpética/cirurgia; Rejeição de enxerto; Complicações pós-operatórias; Recidiva; Estudos retrospectivos

\section{INTRODUÇ̃̃̃O}

A ceratite herpética recorrente causa, freqüentemente, cicatriz corneana, sendo uma das principais causas de perda visual unilateral ${ }^{(1)}$. A recorrência ocorre através da reativação do vírus no gânglio trigeminal, que, pelos nervos da divisão oftálmica do trigêmio, alcança os tecidos periféricos, como a córnea, e aí se replica. Segundo relato, a córnea pode ser o local de latência do vírus ${ }^{(2)}$. O uso de aciclovir oral, $400 \mathrm{mg} 2$ vezes ao dia, tem reduzido, significantemente, a taxa de recorrência da doença herpética genital $^{(3-4)}$, orofacial $^{(5-6)}$ e ocular $^{(7)}$.

O transplante penetrante de córnea muitas vezes é necessário não somente para a reabilitação da visão, mas com objetivo tectônico e ou terapêutico, nos casos em que a resposta ao tratamento específico e de suporte não forem suficientes. Embora alguns estudos revelem que transplante em herpes esteja associado a maior taxa de rejeição e falência ${ }^{(1,8)}$, a taxa de sobrevivência pode chegar a $71 \%$ em 5 anos ${ }^{(9)}$.

Foram avaliados os resultados dos transplantes de córnea em ceratite por herpes simples realizados no período de janeiro de 1993 a outubro de 1998, na Universidade Federal de São Paulo (UNIFESP).

\section{MÉTODOS}

Foram revisados os prontuários de 38 pacientes submetidos a transplante de córnea por ceratite herpética no Setor de Doenças Externas 
Oculares e Córnea do Departamento de Oftalmologia da UNIFESP. O estudo compreendeu todos os pacientes com um mínimo de 6 meses de seguimento pós-operatório e acometimento ocular unilateral, no período de janeiro de 1993 a outubro de 1998. O diagnóstico de ceratite herpética foi baseado na história, exame clínico e resposta terapêutica ao tratamento específico. Foram 24 pacientes do sexo masculino e 14 do feminino, com idade média de 32 anos ( 5 a 74 anos) e tempo médio de doença herpética de 4,7 anos ( 2 meses a 18 anos). Segundo a classificação proposta por Holland e Schwartz ${ }^{(10)}$, as indicações para ceratoplastia penetrante incluíram: ceratite epitelial infecciosa com evolução para cicatriz estromal em 25 olhos $(65,7 \%)$, ceratite estromal necrosante em 8 olhos $(21,1 \%)$, destes, 7 apresentavam perfuração corneana ou descemetocele, e endotelite disciforme em 5 (13,2\%). Foram realizados 31 transplantes penetrantes eletivos (sem atividade da doença por um mínimo de 6 meses), destes, 5 cirurgias tríplices (transplante associado à facectomia com implante intra-ocular) e 7 tectônicos e terapêuticos, ou seja, com doença ativa. Todos os casos tinham indicação de profilaxia antiviral, mas 16 pacientes não usaram antiviral por falta de recursos econômicos e 22 fizeram uso profilático de aciclovir oral na dose de $800 \mathrm{mg} /$ dia, em média, por 4 meses ( 1 a 12 meses) de pós-operatório. Todos usaram corticóide tópico, no mínimo por 6 meses, e em 11 pacientes foi associado corticóide oral. Rejeição endotelial, diagnosticada com o achado da linha endotelial no botão doador, foi tratada com corticóide tópico e subconjuntival e profilaxia com antiviral oral, e a recidiva herpética com aciclovir tópico ou oral. O período de seguimento variou de 6 a 68 meses (média de 21 meses).

A sobrevivência do enxerto foi analisada usando o método de Kaplan-Meier. O teste exato de Fisher foi realizado para avaliar a associação de sobrevivência do enxerto e uso de antiviral profilático, associação de sobrevivência do enxerto e rejeição, rejeição do enxerto e recidiva do herpes no transplante e recidiva e uso do antiviral. O teste do Qui-quadrado foi usado para analisar a associação de rejeição e uso de antiviral. Foi fixado em 5\% o nível para rejeição da hipótese de nulidade.

\section{RESULTADOS}

Dos 38 transplantes realizados, 31 permaneceram transparentes $(81,6 \%)$ e $7(18,4 \%)$ evoluíram com insucesso no período de acompanhamento entre 6 e 68 meses (média de 21 meses). A taxa de sobrevivência dos enxertos foi de 76,7\% em 28 meses (Gráfico 1). Dos sete transplantes tectônicos, 6 mantiveram enxertos transparentes. As causas de insucesso incluíram rejeição endotelial ( 3 casos), recidiva da ceratite herpética seguida de rejeição (1), ceratite bacteriana secundária (1), falência primária do enxerto (1) e glaucoma (1).

A análise, através do teste exato de Fisher, da associação de sobrevivência dos transplantes e o uso ou não de antiviral profilático, não mostrou diferença estatisticamente significante entre os dois grupos $(\mathrm{p}=0,32)$ (Tabela 1$)$.

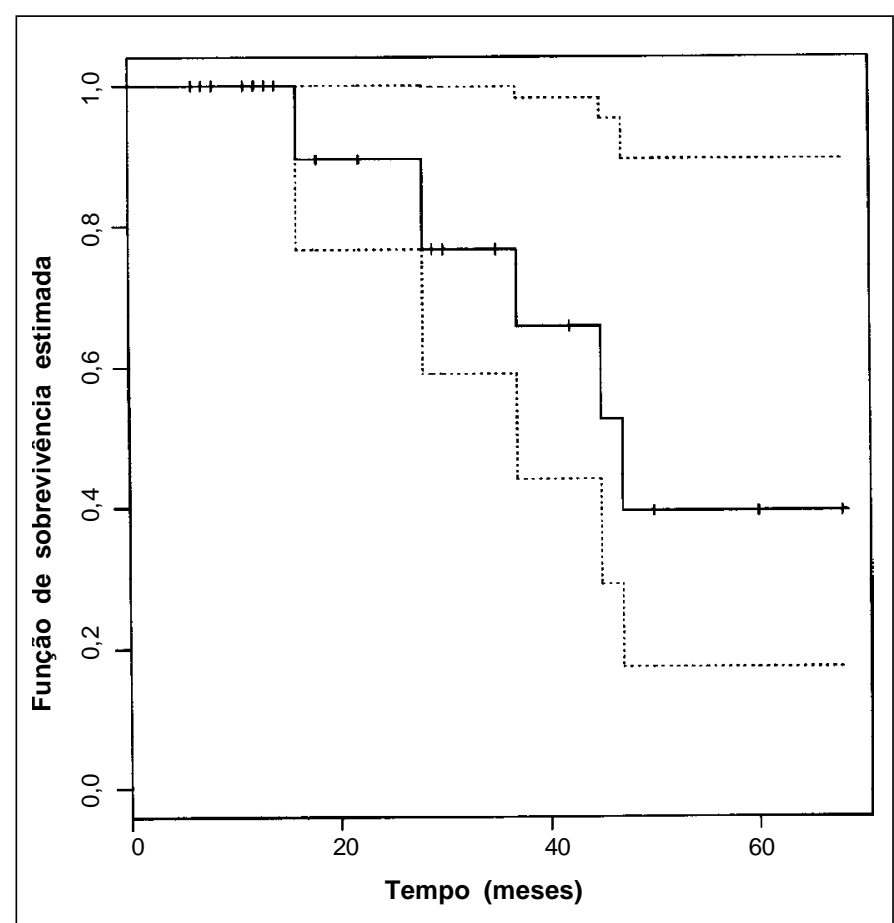

Gráfico 1 - Curva de sobrevivência dos transplantes de córnea em ceratite por herpes simples, realizados entre 1993 e 1998

\begin{tabular}{|c|c|c|c|}
\hline \multirow[t]{2}{*}{ Antiviral } & \multicolumn{2}{|c|}{ Sobrevivência Tx* } & Total \\
\hline & $\begin{array}{c}\text { Sim } \\
\text { no } \quad(\%)\end{array}$ & $\begin{array}{c}\text { Não } \\
\mathrm{n}{ }^{\circ} \quad(\%)\end{array}$ & no $\quad(\%)$ \\
\hline Sim & $19(50,0)$ & $3 \quad(7,9)$ & $22 \quad(57,9)$ \\
\hline Não & $12(31,6)$ & $4(10,5)$ & $16 \quad(42,1)$ \\
\hline Total(\%) & $31(81,6)$ & $7(18,4)$ & $38(100,0)$ \\
\hline
\end{tabular}

Reação de rejeição ocorreu em 14 pacientes $(36,8 \%)$, sendo que em 11 destes no $1^{\circ}$ ano pós-operatório. A avaliação através do teste exato de Fisher mostrou associação estatisticamente significante entre rejeição e falência do transplante $(\mathrm{p}=0,006)$ (Tabela 2). Também foi analisada, através do teste do Qui-quadrado, a associação de rejeição e uso ou não de antiviral e não houve diferença significante.

Quatro pacientes $(10,5 \%)$ apresentaram recidiva da ceratite herpética, localizada na transição do botão do receptor com doador. Nenhum paciente estava usando antiviral no momento da recidiva. Um paciente usou antiviral profilático por 7 meses no período pós-operatório e a recidiva herpética ocorreu no $8^{\circ}$ mês. Todos os pacientes com recidiva tiveram episódios de rejeição, entre 2 a 8 semanas após. A associação de recidiva e rejeição foi estatisticamente significante avaliada pelo teste exato de Fisher ( $p=0,0136$ ) (Tabela 3). A associação de falência do enxerto com recidiva herpética também foi estatisticamente significante (teste exato de Fisher, $p=0,0140$ ). 


\begin{tabular}{|c|c|c|c|}
\hline \multirow[t]{3}{*}{ Rejeição } & \multicolumn{2}{|c|}{ Sobrevivência $T x^{*}$} & Total \\
\hline & Sim & Não & \\
\hline & no $\quad(\%)$ & $\mathrm{n} \circ \quad(\%)$ & no $\quad(\%)$ \\
\hline Sim & $8 \quad(21,1)$ & $6(15,7)$ & $14 \quad(36,8)$ \\
\hline Não & $23(60,5)$ & $1 \quad(2,7)$ & $24 \quad(63,2)$ \\
\hline Total (\%) & $31 \quad(81,6)$ & $7 \quad(18,4)$ & $38(100,0)$ \\
\hline
\end{tabular}

\begin{tabular}{|c|c|c|c|}
\hline \multirow[t]{3}{*}{ Rejeição } & \multicolumn{2}{|c|}{ Recidiva } & Total \\
\hline & Sim & Não & \\
\hline & no $\quad(\%)$ & no $\quad(\%)$ & no $\quad(\%)$ \\
\hline Sim & $4 \quad(10,5)$ & $10 \quad(26,3)$ & $14 \quad(36,8)$ \\
\hline Não & $0 \quad(0,0)$ & $24 \quad(63,2)$ & $24 \quad(63,2)$ \\
\hline Total & $4 \quad(10,5)$ & $34 \quad(89,5)$ & $38(100,0)$ \\
\hline
\end{tabular}

As complicações mais freqüentes, além de rejeição e recidiva herpética, foram: glaucoma $(13,1 \%)$, defeito epitelial persistente $(7,9 \%)$, ceratite bacteriana secundária $(5,7 \%)$, catarata $(5,7 \%)$ e membrana pupilar $(2,6 \%)$. Em 2 transplantes, com defeito epitelial persistente, foi realizado recobrimento conjuntival.

A acuidade visual pré-operatória variou de projeção luminosa (PL) a 0,2 e a acuidade visual pós-operatória de PL a 1,0 (Gráfico 2). Em 60\% dos pacientes a acuidade visual foi melhor ou igual a 0,25 e em $36,8 \%$, maior que 0,5 .

\section{DISCUSSÃO}

Transplante de córnea é uma alternativa no tratamento de ceratite por herpes simples para restabelecer a visão, manter a integridade do globo ocular e ou com finalidade terapêutica. A sobrevivência do enxerto em doença herpética é variável, com taxas de $71 \%$ em 5 anos e $58 \%$ em 10 anos $^{(9)}$. Nesta pesquisa foi observado $76,7 \%$ de sobrevivência do enxerto em 28 meses de pós-operatório; este achado está de acordo com o descrito na literatura. A taxa encontrada de $39,4 \%$ em 47 meses de seguimento, demonstrado na curva de sobrevivência estimada de Kaplan-Meier (Gráfico 1), é, provavelmente, devido ao fato de que poucos pacientes foram acompanhados até este período, além disso, esses pacientes estavam mais gravemente acometidos.

Vários estudos revelaram que o uso de antiviral (aciclovir) oral reduz a recorrência da doença herpética ${ }^{(7-9,11)}$. O HEDS

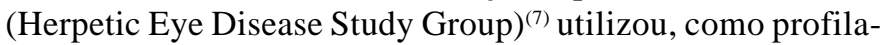
xia, $400 \mathrm{mg} 2$ vezes ao dia pelo período de um ano pós-operatório de transplante de córnea. Neste presente estudo, não houve diferença estatisticamente significante na sobrevivência do

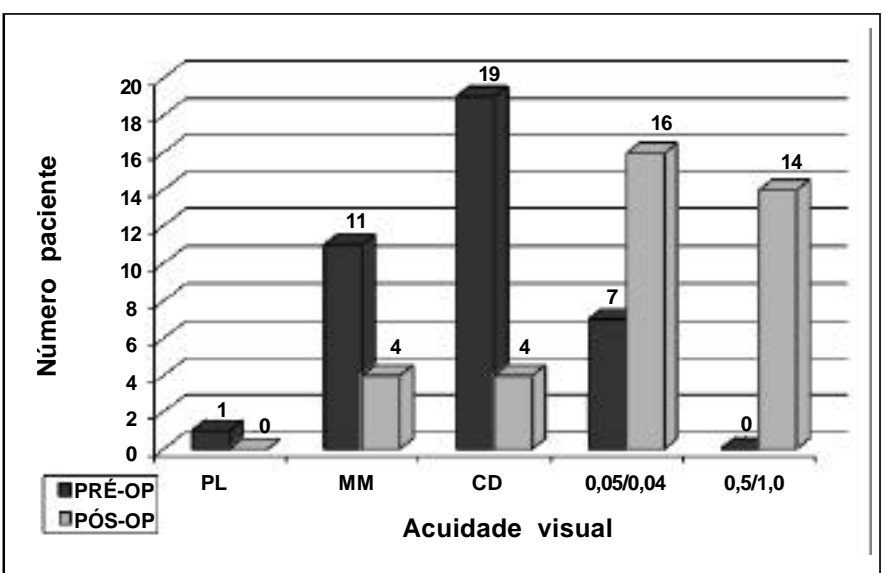

Gráfico 2 - Acuidade visual no pré e pós-operatório dos pacientes submetidos a transplante de córnea em ceratite por herpes simples

enxerto com o uso ou não de antiviral profilático, provavelmente pelo tamanho da amostra, pelo tempo do uso do aciclovir (média de 4 meses) e porque a escolha dos pacientes que usaram o aciclovir não foi randomizada.

Reação de rejeição ao enxerto em herpes é descrito em 20 a $56 \%$ dos $\operatorname{casos}^{(1,8)}$. A taxa de rejeição endotelial nesta pesquisa foi de $36,8 \%$ e não houve diferença significante entre os dois grupos (uso e não uso de antiviral), semelhante ao encontrado em outro trabalho ${ }^{(8)}$. Rejeição está associada à falência do transplante, por estar relacionada à recorrência do herpes assim como à infecção bacteriana ${ }^{(11)}$ no enxerto. Dos 14 pacientes que apresentaram reação de rejeição, $5(35,7 \%)$ evoluíram para falência. No grupo que não apresentou rejeição $(25$ pacientes) apenas dois (8\%) evoluíram para falência, sendo a associação de falência e rejeição estatisticamente significante.

Estudos revelam que a recidiva da ceratite herpética no enxerto varia de 0 a $39 \%^{(8,12-14)}$ aumentando com o tempo de seguimento ${ }^{(15)}$, ocorrendo caracteristicamente na transição do bordo do doador com o receptor. Foi encontrado, neste grupo avaliado, em 10,5\% dos casos e todos apresentaram rejeição, sendo a associação estatisticamente significante. Dos 4 pacientes, apenas um usou antiviral profilático. O tamanho da amostra não permitiu avaliar estatisticamente a associação de recidiva herpética com o uso ou não do antiviral.

Com os antivirais disponíveis, poucos olhos são submetidos a transplante à quente, nos quais o prognóstico é pobre, com apenas $44 \%$ dos enxertos transparentes em 2 anos $^{(15)}$, e, embora o resultado nesta série tenha sido bom (apenas 1 caso evoluiu para falência), o número de transplantes com úlcera ativa foi pequeno ( 7 casos). Nestes casos tentamos inicialmente tratar a úlcera usando medidas conservadoras como adesivo tecidual, lente de contato terapêutica ou mesmo recobrimento conjuntival, antes de indicar o transplante.

O prognóstico visual é bom em olhos com doença inati$\mathrm{va}^{(12)}$, e podemos confirmar com nossos resultados nos quais a acuidade visual foi melhor que $0,25 \mathrm{em} 60 \%$ dos pacientes. 


\section{ABSTRACT}

Purpose: To evaluate the results of corneal transplantation for herpes simplex keratitis. Methods: The records of thirtyeight patients who underwent penetrating keratoplasty for herpes simplex keratitis, from 1993 to 1998 were retrospectively reviewed. Postoperative follow-up periods ranged from 6 to 68 months (mean 21). Results: The survival rate of a clear graft was $81.6 \%$. Allograft rejection was observed in $36.8 \%$ and herpetic recurrence occurred in $10.5 \%$. Visual acuities of $20 / 80$ or better were achieved in $60 \%$. Prophylactic antiviral treatment was not associated with increase in corneal graft survival rate. Conclusion: Better results have been achieved on keratoplasty for herpetic keratitis.

Keywords: Corneal transplantation; Keratitis herpetic/surgery; Graft rejection; Postoperative complications; Recurrence; Retrospective studies

\section{REFERÊNCIAS}

1. Cohen EJ, Laibson PR, Arentsen JJ. Corneal transplantation for herpes simplex keratitis. Am J Ophthalmol 1983;95:645-50.

2. Pavan-Langston D, Rong B, Dunkel EC. Extraneuronal herpetic latency: Animal and human corneal studies. Acta. Ophthalmol (Copenh) 1989;192 Suppl:135-41.
3. Mertz GJ, Jones CC, Mills J, et al. Long-term acyclovir suppression of frequently recurring genital herpes simplex virus infection: a multicenter double-blind trial. JAMA 1988;260:201-6.

4. Mattison HR, Reichman RC, Benedetti J, et al. Double-blind, placebo-controlled trial comparing long-term suppressive with short-term oral acyclovir therapy for management of recurrent genital herpes. Am J Med 1988; $85(2 \mathrm{~A}): 20-5$

5. Spruance SL, Hamill ML, Hoge WS, Davis LG, Mills J. Acyclovir prevents reactivation of herpes simplex labialis in skiers. JAMA 1988;260:1597-9.

6. Rooney JF, Straus SE, Mannix ML, et al. Oral acyclovir to suppress frequently recurrent herpes labialis: a double-blind, placebo-controlled trial. Ann Intern Med 1993;118:268-72.

7. The Herpetic Eye Disease Study Group. Acyclovir for the prevention of recurrent herpes simplex virus eye disease. New Engl J Med 1998;339:300-6.

8. Barney NP, Foster S. A prospective randomized trial of oral acyclovir after penetrating keratoplasty for herpes simplex keratitis. Cornea 1994;13:232-6.

9. Ficker LA, Kirkness CM, Rice NS, Steele AD. The changing management and improved prognosis for corneal grafting in herpes simplex keratitis. Ophthalmology 1989;96:1587-96.

10. Holland, EJ, Schwartz, GS. Classification of herpes simplex virus keratitis. Cornea 1999;18:144-54.

11. Moyes AL, Sugar A, Musch DC, Barnes RD. Antiviral therapy after penetrating keratoplasty for herpes simplex keratitis. Arch Ophthalml 1994;112:601-7.

12. Tambasco FP, Cohen EJ, Nguyen LH, Rapuano CJ, Laibson PR. Oral acyclovir after penetrating keratoplasty for herpes simplex keratitis. Arch Ophthalmol 1999; $117: 445-9$

13. Sterk CC, Jager MJ, Swart-vd Berg M. Recurrent herpetic keratitis in penetrating keratoplasty. Doc Ophthalmol 1995;90:29-33.

14. Lomholt JA, Baggesen K, Ehlers N. Recurrence and rejection rates following corneal transplantation for herpes simplex keratitis. Acta Ophthalmol Scand 1995;73:29-32.

15. Cobo LM, Coster DJ, Rice N, Jones BR. Prognosis and management of corneal transplantation for herpetic keratitis. Arch Ophthalmol 1980;98:1755-9.

\section{Curso de Ultra-som e Imagem \\ 06 e 07 de Dezembro de 2002 São Paulo - SP}

Promoção: CEO Prof. Moacyr E. Álvaro

INFORMAÇÕES: tel.: (1 1) 5575-4243 